COMMENTS ON BECHTEL'S "RADIO FREQUENCY INTERFERENCE TEST PROCEDURE FOR INSTRUMENT AND CONTROL SYSTEMS"

R. J. Kane

September 21, 2011 
This document was prepared as an account of work sponsored by an agency of the United States government. Neither the United States government nor Lawrence Livermore National Security, LLC, nor any of their employees makes any warranty, expressed or implied, or assumes any legal liability or responsibility for the accuracy, completeness, or usefulness of any information, apparatus, product, or process disclosed, or represents that its use would not infringe privately owned rights. Reference herein to any specific commercial product, process, or service by trade name, trademark, manufacturer, or otherwise does not necessarily constitute or imply its endorsement, recommendation, or favoring by the United States government or Lawrence Livermore National Security, LLC. The views and opinions of authors expressed herein do not necessarily state or reflect those of the United States government or Lawrence Livermore National Security, LLC, and shall not be used for advertising or product endorsement purposes.

This work performed under the auspices of the U.S. Department of Energy by Lawrence Livermore National Laboratory under Contract DE-AC52-07NA27344. 


\section{COMMENTS ON BECHTEL'S “RADIO FREQUENCY INTERFERENCE TEST PROCEDURE FOR INSTRUMENT AND CONTROL SYSTEMS"}


LLNL-TR-500095

DISCLAIMER

This document was prepared as an account of work sponsored by an agency of the United States government. Neither the United States government nor Lawrence Livermore National Security, LLC, nor any of their employees makes any warranty, expressed or implied, or assumes any legal liability or responsibility for the accuracy, completeness, or usefulness of any information, apparatus, product, or process disclosed, or represents that its use would not infringe privately owned rights. Reference herein to any specific commercial product, process, or service by trade name, trademark, manufacturer, or otherwise does not necessarily constitute or imply its endorsement, recommendation, or favoring by the United States government or Lawrence Livermore National Security, LLC. The views and opinions of authors expressed herein do not necessarily state or reflect those of the United States government or Lawrence Livermore National Security, LLC, and shall not be used for advertising or product endorsement purposes. 


\section{BACKGROUND}

A copy of the Radio Frequency Interference Test Procedure and sketches for the interconnections was provided to me by Mazhar Haq for review. The intent is to determine whether adverse interactions will be observed at the Russell City Energy Center (RCEC) site due to coupled RF fields from the KFAX / KTRB AM broadcast antenna array. Construction of the RCEC has been impacted by the generation of RF currents in closed loops when large cranes are used for moving materials, appropriate measures have been employed to eliminate safety issues affecting the workers. The impact of the larger RF fields on the sensors and control actuators is yet a concern.

The Test Procedure describes the use of a temporary, 100 foot tall assembly of raceway, conduit, wiring and sensors that will be supported by a crane in the area of heat recovery system located closest to the antenna array. Sensors and actuators will be operated to observe whether the normal daytime operation of the broadcast transmitters results in functional impairment.

\section{REVIEW COMMENTS}

First, the topic of worker safety should be considered. The structure is to be moved into position using a dielectric sling and then its base locally grounded. Once the structure is grounded it presents no induced RF energy threat to the workers. The crane supporting the structure might best be positioned radially beyond the test structure

The shielding of the raceway structure will minimize the generation of a voltage on the cables but the treatment of the sensors at the top and bottom are not described; these should be attached in their normal manner and are expected to be grounded to the structure. If a sensor is not case-grounded then I suggest the use of an RF voltmeter or the digital storage oscilloscope (DSO) first to ensure that the potential is known before the control wiring is handled at the base of the assembly.

Note that if there is a noticeable voltage observed under the simulated installation configuration then maintenance operations may require further development as the facility is completed.

The procedure lists the steps for verifying operation of the sensors and actuators and is minimal in its extent. Quantitative measurements are included using the RF voltmeter in step 6.2.13 but I also recommend use of a spectrum analyzer if one is available. The following measurements and observations would be useful for site characterization as well as for troubleshooting:

- Magnitude of carrier signals -860 and $1100 \mathrm{kHz}$

- Ensure that the status of the two transmitters is known at the time of testing

- Differential and common mode signals on wires and structure

- Excessive harmonic levels of the carrier signals could indicate non-linearity in the test system

- $\quad$ Possible non-linear mixing producing new signals at 240 and $1960 \mathrm{kHz}$

- Non-linear interaction of both signals in a non-linear circuit - saturation or clipping

- Sensor linearity and saturation

- Ensure that the temperature measurement is correct and varies as expected, try to do something more than a single point measurement.

- $\quad$ Effects on power supplies

- Some power supplies may have limited isolation response in their feedback regulator circuit. Suitable batteries or additional filtering should be available to test the power source if anomalous operation is noted. 
- The HART communications protocol relies on a small signal impressed on the 4-20 mA current loop control. A loop of wire oriented such that it couples to the AM signal could be affected. This depends on the receiver architecture and a filter is listed in the mitigation section.

Also note that the DSO might have selectable input impedances, this should be checked to ensure that it is not $50 \mathrm{Ohms}$ if the external termination is also used.

The basic goals of determining if there is a problem should be met by the procedure as provided. My recommendations for the use of a spectrum analyzer as well as exercising sensors and actuators over some functional range would show if the response is correct rather than it be assumed so from a single point test.

A simple simulation was performed to estimate the fields in the region where the HRSG will be installed. The attached screen-shot shows the E-field reaching values of $\sim 20 \mathrm{~V} / \mathrm{m}$ near the top of the structure and possibly higher immediately adjacent to the simulated structure. These voltages are not a human safety concern but they exceed the IEC and OSHA Standards for RF immunity in instrumentation. The Hatfield and Dawson report referenced a level of $3 \mathrm{~V} / \mathrm{m}$ and $10 \mathrm{~V} / \mathrm{m}$ is a value encountered for US medical instrumentation tolerance. The corresponding induced currents are also small; approximately $50 \mathrm{~mA}$. The structural shielding will reduce the levels provided the cabling, conduit and raceways are all well-connected and grounded. 


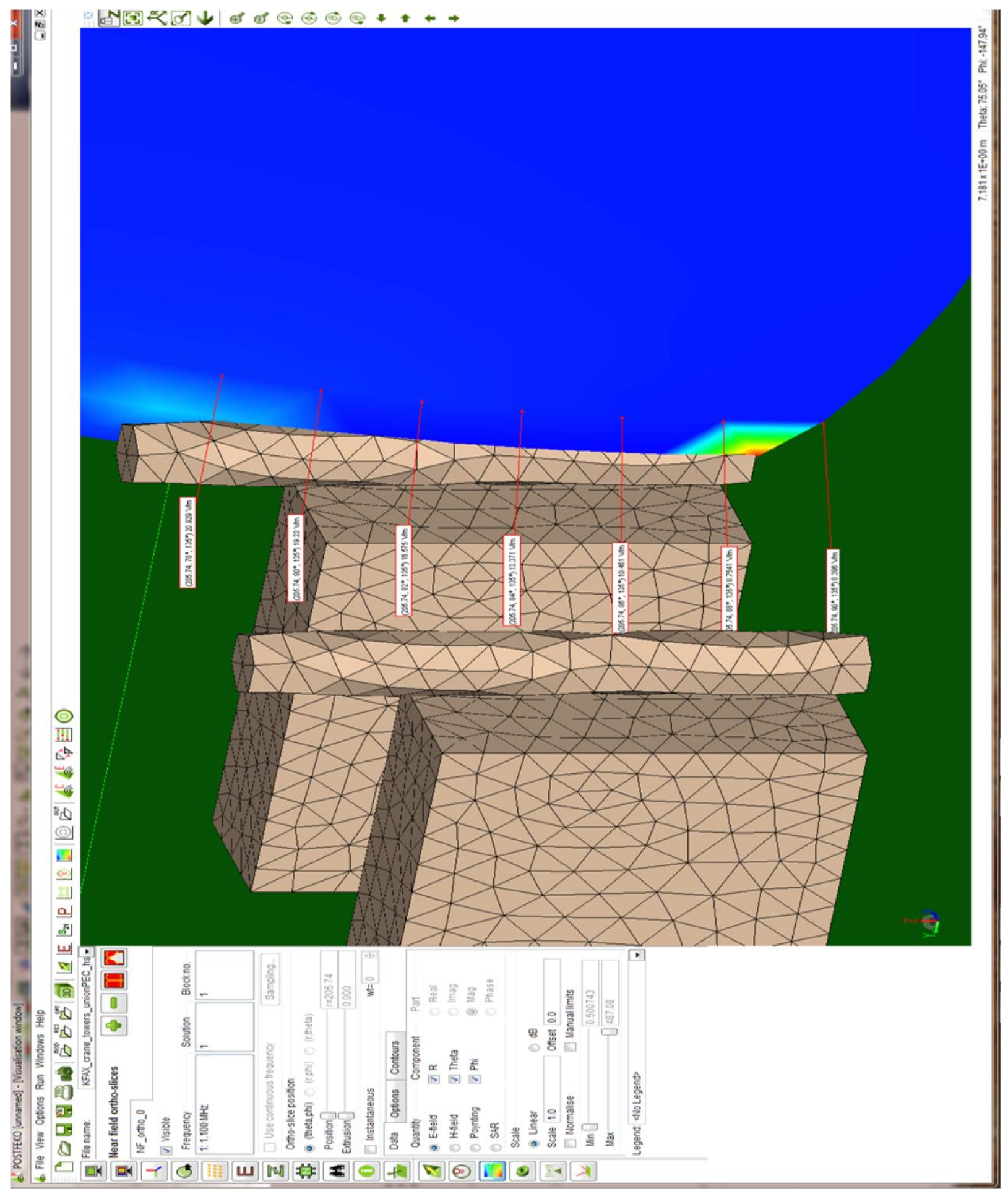

This figure shows the electric field (blue surface) in the vicinity of the HRSG structures where a perfectly conducting (PEC) ground has been used. The use of a PEC and 'real' ground have been compared and there is little difference for the purpose of this review. 